\title{
The influence of postoperative mitral valve function on the late recurrence of atrial fibrillation after the maze procedure combined with mitral valvuloplasty
}

\author{
Joon Bum Kim, MD, ${ }^{a}$ Seung Hyun Lee, MD, ${ }^{\mathrm{a}}$ Sung Ho Jung, MD, ${ }^{a}$ Sung Cheol Yun, PhD, ${ }^{\mathrm{b}}$ \\ Suk Jung Choo, MD, ${ }^{a}$ Cheol Hyun Chung, MD, ${ }^{\mathrm{a}}$ Hyun Song, MD, ${ }^{\mathrm{c}}$ and Jae Won Lee, MD ${ }^{\mathrm{a}}$
}

\begin{abstract}
Objectives: Although a number of reports have identified risk factors for postoperative recurrence of atrial fibrillation after the maze procedure, no studies have investigated the influence of postoperative mitral valve disease on atrial fibrillation recurrence after mitral valvuloplasty combined with the maze procedure.
\end{abstract}

\begin{abstract}
Methods: Between January 1999 and October 2006, 228 patients underwent the maze procedure and concomitant mitral valve repair. There were 4 early deaths. Of the early survivors, 206 patients with restored sinus rhythm were chosen for analysis. During a median follow-up of 50.8 months (range, 0.6-122.8 months), there were 35 patients who had mitral regurgitation $(n=26)$ or mitral stenosis $(n=9)$. Patients who had postoperative mitral valve disease (disease group, $\mathrm{n}=35$ ) were compared with those who did not (control group, $\mathrm{n}=171$ ) for late recurrence of atrial fibrillation.
\end{abstract}

Results: Twenty-eight patients experienced late recurrence of atrial fibrillation. The disease group had a higher atrial fibrillation recurrence rate than the control group (5-year atrial fibrillation-free rates were $65.2 \% \pm 10.3 \%$ and $85.8 \% \pm 3.4 \%$, respectively; $P=.014$ ). Univariate and multivariate analyses of a range of variables revealed that a larger preoperative left atrial size (hazard ratio, 2.61; $P=.041$ ), the use of microwave ablation rather than cryoablation (hazard ratio, 2.33; $P=.041$ ), the presence of early ( $<3$ months) postoperative atrial fibrillation events (hazard ratio, 3.75; $P=.001$ ), and the presence of postoperative mitral valve disease (hazard ratio, $3.67 ; P=.005)$ were independent predictors for late atrial fibrillation recurrence.

Conclusions: Maze procedure outcomes were negatively affected by postoperative mitral valve disease after mitral valvuloplasty, as evidenced by greater atrial fibrillation recurrence. (J Thorac Cardiovasc Surg 2010;139:1170-6)

The maze operation accompanied by mitral valve (MV) surgery is regarded as the best option for terminating atrial fibrillation $(\mathrm{AF})$ in patients with mitral disease and $\mathrm{AF}{ }^{1}$ However, long-term follow-up of patients who undergo the maze procedure suggests that late $\mathrm{AF}$ recurrence limits the benefits of the procedure. ${ }^{2-6}$ Studies investigating patients at greater risks of $\mathrm{AF}$ recurrence revealed that preoperative conditions, such as longer AF duration, a fine AF-wave pattern, a larger left atrial (LA) size, older age, a higher left ventricular mass index, and a higher cardiothoracic ratio, were positive predictors of $\mathrm{AF}$ recurrence. ${ }^{2-5}$

\footnotetext{
From the Departments of Thoracic and Cardiovascular Surgery ${ }^{\mathrm{a}}$ and Preventive Medicine, ${ }^{\mathrm{b}}$ Asan Medical Center, University of Ulsan College of Medicine, and the Department of Thoracic and Cardiovascular Surgery, ${ }^{\mathrm{c}}$ Seoul Saint Mary's Hospital, College of Medicine, Catholic University of Korea, Seoul, South Korea. Disclosures: None.

Received for publication Feb 21, 2009; revisions received June 9, 2009; accepted for publication July 16, 2009; available ahead of print Sept 23, 2009.

Address for reprints: Jae Won Lee, MD, Department of Thoracic and Cardiovascular Surgery, Asan Medical Center, University of Ulsan College of Medicine, 388-1 Pungnap-dong Songpa-gu, Seoul 138-736, South Korea (E-mail: jwlee@amc. seoul.kr).

$0022-5223 / \$ 36.00$

Copyright (c) 2010 by The American Association for Thoracic Surgery doi:10.1016/j.jtcvs.2009.07.042
}

Increased pressure and volume load to the LA caused by remnant or recurrent mitral disease after mitral valvuloplasty can induce LA chamber enlargement. Because these processes are regarded as the source of AF generation in patients with mitral disease in general, patients with postoperative MV disease are expected to have a greater risk of AF recurrence after the maze operation. However, to our knowledge, no studies have investigated whether remnant or recurrent MV disease after MV repair is associated with an increased risk of $\mathrm{AF}$ recurrence after the maze operation.

The aim of this study was to investigate the influence of postoperative $\mathrm{MV}$ dysfunction on late $\mathrm{AF}$ recurrence after the maze procedure combined with MV repair. For this, we performed univariate and multivariate risk factor analyses for recurrent $\mathrm{AF}$ after surgical intervention, including postoperative MV disease as a candidate risk variable.

\footnotetext{
MATERIALS AND METHODS Patients

From January 1999 to October 2006, 228 patients underwent the maze procedure combined with MV repair in Asan Medical Center, Seoul, South Korea. The maze procedure and MV repair were performed concomitantly with or without other cardiac procedures. There were 4 early deaths. Fifteen patients did not recover sinus rhythm, and of these patients, 3 underwent permanent pacemaker insertion. One patient was lost to follow-up. Of the early survivors, $208(91.2 \%)$ had restored sinus rhythm. Patients were
} 

Abbreviations and Acronyms
$\mathrm{AF}=$ atrial fibrillation
$\mathrm{CI}=$ confidence interval
$\mathrm{HR}=$ hazard ratio
$\mathrm{LA}=$ left atrium
$\mathrm{MR}=$ mitral regurgitation
$\mathrm{MV}=$ mitral valve

divided into 2 groups according to the presence or absence of postoperative MV disease. Postoperative MV disease was defined as follows: (1) mitral regurgitation (MR) of greater than grade 2 or (2) mitral stenosis defined by an MV area of less than $2.0 \mathrm{~cm}^{2}$ or a transmitral peak pressure gradient of greater than $10 \mathrm{~mm} \mathrm{Hg}$. There were 37 patients who met these criteria ( 28 with MR and 9 with mitral stenosis). Two patients in the postoperative MV dysfunction group underwent reoperation. One patient revealed failed mitral repair on predischarge echocardiographic analysis and underwent tissue valve replacement on postoperative day 14. Another patient showed late MR recurrence caused by chordae rupture and underwent redo mitral repair (the Alfieri technique) on postoperative day 547. Because these 2 patients do not represent the true postoperative MV dysfunction group after reoperation, they were excluded from the present study. Finally, 35 patients with postoperative MV dysfunction were included in this study and were defined as the disease group.

Those who did not show postoperative MV disease were defined as the control group $(n=171)$. The study compared the 2 groups in terms of AF recurrence, changes in LA size, and transmitral A-wave characteristics.

This study was approved by our institution's ethics committee/institutional review board.

\section{Surgical Procedures}

A median sternotomy approach was used for most patients $(n=169$ [82.0\%]), and a right anterolateral minithoracotomy approach with the AESOP 3000 system (Computer Motion, Inc, Santa Barbara, Calif) was used in the most recent patients $(\mathrm{n}=37[18.0 \%])$. Conventional ascending aorta and bicaval cannulation was used for the sternotomy approach, and the minimally invasive approach involved peripheral cannulation through the right internal jugular vein, right femoral vein, and right femoral artery. Myocardial protection was achieved with antegrade and retrograde tepid blood cardioplegia. After aortic crossclamping, MV exposure was obtained through an LA incision.

A modification of the maze procedure was performed, the details of which have been described previously. ${ }^{7}$ LA size was reduced by means of generous resection of redundant atrial tissue off the posterior LA wall parallel to the posterior mitral annulus. The degree of LA wall resection was determined based on preoperative LA size, with a target postoperative LA size of less than $50 \mathrm{~mm}$.

\section{Echocardiography}

Two-dimensional echocardiographic analysis and Doppler color-flow imaging were performed on all patients with a Hewlett-Packard Sonos 2500 or 5500 imaging system equipped with a $2.5-\mathrm{MHz}$ transducer (Hewlett-Packard, Andover, Mass). Preoperative echocardiographic analysis (both transthoracic and transesophageal) was performed in all patients within 2 months before the operation. Postoperative transthoracic echocardiographic evaluation was performed at 3 and 6 months and every year thereafter. Doppler flow mapping was used for semiquantitation of MR; at least grade 3 MR was defined as a distal regurgitant jet area of greater than 8 $\mathrm{cm}^{2}$ or a radius of proximal flow convergence of greater than $0.5 \mathrm{~cm}$ at the aliasing velocity of $40 \mathrm{~cm} / \mathrm{s}$. MV area was estimated by using the pressure half-time method. LA size was measured based on its anteroposterior diameter on the parasternal long-axis view at end-systole.

\section{Postoperative Rhythm Follow-up}

Postoperatively, in-patient rhythms were monitored daily by using standard 12-channel surface electrocardiographic analysis. Patients were routinely evaluated with 24-hour Holter monitoring before hospital discharge. Follow-up electrocardiograms were performed at 3- to 6-month intervals during the first 2 years and every year thereafter. Any symptoms suspicious of arrhythmia were assessed by means of 24-hour Holter monitoring during follow-up. Recurrences or events of AF during the initial postablation blanking period of 3 months are defined as early events. A failure of the maze procedure defines any recurrent $\mathrm{AF}$, atrial tachycardia, or atrial flutter at least 3 months after stopping antiarrhythmic agents as beyond the initial blanking period. The results are presented in "Freedom from AF without antiarrhythmic agent." The definitions on early events (initial blanking period) and a failure of the maze procedure were based on the consensus of reporting standards made by the Heart Rhythm Society Task Force on Catheter and Surgical Ablation of AF. ${ }^{8}$

All data were collected prospectively and stored for later assessment in a specially designed and regimented database.

\section{Postoperative Management}

Postoperative AF, atrial flutter, atrial tachycardia, frequent atrial premature beats, and recurrent atrial tachyarrhythmia were treated with amiodarone, which was commenced at $1200 \mathrm{mg} / \mathrm{d}$ and tapered according to the patients' rhythm status. A rapid ventricular rate despite the amiodarone therapy was controlled with $\beta$-blockers or calcium-channel blockers. Patients were routinely anticoagulated with warfarin for 3 to 6 months postoperatively with a target international normalized ratio of 1.5 to 2.5 at the discretion of the attending surgeon. The maintenance of anticoagulation therapy thereafter was determined according to the individual patient's risk factors of thromboembolism and cardiac rhythm status. Postoperative AF or the absence of effective atrial contraction resulted in anticoagulation therapy that was continued until both sinus rhythm and atrial contractility were restored.

\section{Statistics}

Categorical variables were presented as frequencies and percentages and were compared by using the $\chi^{2}$ or Fisher's exact tests. Continuous variables were expressed as means \pm standard deviations or medians with ranges and were compared by using the Student's unpaired $t$ test or the Mann-Whitney $U$ test, as appropriate. Kaplan-Meier curves were used to delineate freedom from MV disease and freedom from $\mathrm{AF}$, and log-rank tests were used to compare the differences in AF-free rates between groups. Stratified survival curves (freedom from AF without an antiarrhythmic agent) were plotted to explore unadjusted differences for variables of interest. For multivariate analyses, the updated covariate Cox models were used to examine the association of baseline characteristics with time to $\mathrm{AF}$ recurrence. ${ }^{9}$ Variables with a $P$ value .20 or less in univariate analyses were candidates for the multivariable updated covariate Cox models. Multivariate analyses involved a backward elimination technique, and only variables with a $P$ value of less than .10 were used in the final model. Results were expressed as hazard ratios (HRs) with 95\% confidence intervals (CIs). All reported $P$ values are 2-sided. SAS software version 9.1 (SAS Institute, Inc, Cary, NC) and SPSS version 12 were used for the statistical analysis.

\section{RESULTS}

\section{Baseline Characteristics}

The median age at the time of the operation was 50 years (range, 18-80 years), and $114(55.3 \%)$ patients were women. Clinical follow-up was completed with all patients, with a median follow-up period of 50.8 months 
TABLE 1. Preoperative patient profiles

\begin{tabular}{|c|c|c|c|}
\hline & Control group & Disease group & $P$ value \\
\hline No. of patients & 171 & 35 & \\
\hline Age (y), median (range) & $50(18-80)$ & $50(30-69)$ & .838 \\
\hline Female sex (no.) & 91 & 23 & .175 \\
\hline Cardiothoracic ratio $(\%)$ & $58.7 \pm 8.4$ & $58.9 \pm 11.5$ & .897 \\
\hline $\begin{array}{l}\text { Presence of coronary } \\
\text { disease (no.) }\end{array}$ & 22 & 4 & 1.00 \\
\hline Previous cardiac surgery (no.) & 5 & 2 & .339 \\
\hline Diagnosis & & & .346 \\
\hline Mitral regurgitation (no.) & 126 & 23 & \\
\hline Mitral stenosis (no.) & 12 & 5 & \\
\hline Mitral stenoregurgitation (no.) & 33 & 7 & \\
\hline Cause of MV disease & & & .058 \\
\hline Degenerative (no.) & 81 & 11 & .095 \\
\hline Rheumatic (no.) & 77 & 21 & .120 \\
\hline Ischemic (no.) & 11 & 1 & .695 \\
\hline Infective (no.) & 2 & 1 & \\
\hline Congenital (no.) & 0 & 1 & \\
\hline \multicolumn{4}{|l|}{ Echocardiographic data } \\
\hline LV ejection fraction $(\%)$ & $55.3 \pm 11.0$ & $55.4 \pm 10.2$ & .961 \\
\hline LA dimension $(\mathrm{mm})$ & $60.1 \pm 9.7$ & $60.8 \pm 8.4$ & .727 \\
\hline $\begin{array}{l}\text { LV end-systolic } \\
\text { diameter }(\mathrm{mm})\end{array}$ & $42.5 \pm 8.7$ & $39.7 \pm 7.0$ & .131 \\
\hline $\begin{array}{l}\text { LV end-diastolic } \\
\text { diameter }(\mathrm{mm})\end{array}$ & $62.2 \pm 9.9$ & $59.2 \pm 8.6$ & .125 \\
\hline \multicolumn{4}{|l|}{ AF profiles } \\
\hline $\begin{array}{l}\text { AF duration, years, } \\
\text { median (range) }\end{array}$ & $2(0-25)$ & $3(0-20)$ & .331 \\
\hline Paroxysmal AF (no.) & 21 & 4 & $>.999$ \\
\hline $\begin{array}{c}\text { Fine }(<1 \mathrm{~mm}) \mathrm{AF} \\
\text { wave (no.) }\end{array}$ & 72 & 14 & .985 \\
\hline
\end{tabular}

Data represent means \pm standard deviations. $M V$, Mitral valve; $L V$, left ventricular; $L A$, left atrial; $A F$, atrial fibrillation. Data represent mean (SD).

(range, 0.6-122.8 months). Acquisition of electrocardiograms and echocardiographic data for more than 12 months postoperatively was possible in $193(93.6 \%)$ patients. The control and disease groups were similar in terms of preoperative demographic characteristics, echocardiographic profiles, and clinical manifestation of MV disease and AF (Table 1). LA wall resection was preformed for 186 $(90.3 \%)$ patients, and both groups had a similar proportion of patients who underwent the LA reduction procedure $(P$ $=.538$ ). Ring annuloplasty was used more frequently in the control group, whereas the papillary muscle-splitting technique was used more frequently in the disease group. The 2 groups were similar in terms of concomitant cardiac operations (Table 2).

\section{Immediate and Long-Term Clinical Outcomes}

There were 3 late strokes and 7 late deaths. The overall cerebrovascular accident-free survival rate was $96.9 \% \pm$ $1.3 \%$ at 5 years. Of the 35 patients in the disease group, echocardiographic analysis detected postoperative MV
TABLE 2. Surgical procedures

\begin{tabular}{lccc}
\hline & $\begin{array}{c}\text { Control } \\
\text { group }\end{array}$ & $\begin{array}{c}\text { Disease } \\
\text { group }\end{array}$ & $\begin{array}{c}\boldsymbol{P} \\
\text { value }\end{array}$ \\
\hline No. of patients & 171 & 35 & \\
Cardiopulmonary bypass time (min) & $159.4 \pm 43.7$ & $165.4 \pm 45.1$ & .469 \\
Aortic clamping time (min) & $114.1 \pm 32.3$ & $115.5 \pm 31.0$ & .817 \\
MV procedure & & & \\
Ring annuloplasty (no.) & 156 & 27 & $.016^{*}$ \\
Commissurotomy (no.) & 31 & 11 & .105 \\
Commissural repair (no.) & 13 & 0 & .131 \\
Triangular or quadrangular & 24 & 6 & .605 \\
$\quad$ resection (no.) & & & \\
Leaflet mobilization (no.) & 26 & 8 & .316 \\
New chordae formation (no.) & 40 & 4 & .173 \\
Papillary muscle splitting (no.) & 16 & 9 & $.019 *$ \\
Annular plication or sliding & 8 & 3 & .351 \\
$\quad$ technique (no.) & & & \\
Leaflet patch or extension (no.) & 9 & 2 & $>.999$ \\
Chordae transfer (no.) & 2 & 0 & $>.999$ \\
Alfieri technique (no.) & 2 & 2 & .135 \\
Cardiac cooperation & & & \\
Tricuspid valve repair (no.) & 62 & 18 & .759 \\
$\quad$ Ring annuloplasty (no.) & 41 & 12 & \\
Kay method (no.) & 8 & 1 & \\
$\quad$ De Vega method (no.) & 13 & 3 & \\
Other cardiac procedures & & & \\
$\quad$ Aortic valve replacement (no.) & 15 & 4 & .339 \\
$\quad$ Aortic valve repair (no.) & 2 & 3 & \\
$\quad$ Coronary artery bypassing (no.) & 14 & 3 & \\
$\quad$ ASD, VSD, PDA (no.) & 6 & 1 & \\
$\quad$ Aortic operation (no.) & 1 & 0 & \\
$\quad$ Others (no.) & & 0 & \\
Minimally invasive approach (no.) & 33 & 4 & \\
Alternative energy sources for & & & \\
$\quad$ the maze procedure (no.) & & & \\
Cryoablation (no.) & & & \\
Microwave ablation (no.) & & & \\
\hline
\end{tabular}

$M V$, Mitral valve; $A S D$, atrial septal defect; $V S D$, ventricular septal defect; $P D A$, patent ductus arteriosus. $* P<.05$.

disease in 3 before discharge, whereas the remaining 32 were detected during follow-up. In terms of valvulopathy response to medical therapy, improvement to regression of MR of grade 2 or less was observed in 15 patients, and there was no response or aggravation in the remaining 20 patients. The overall postoperative MV disease-free rates were $84.1 \% \pm 2.7 \%$ at 3 years and $79.0 \% \pm 3.4 \%$ at 5 years (Figure 1). Although log-rank-univariate risk factor analysis identified no use of an annuloplasty ring $(P=.031)$ and use of the papillary muscle-splitting technique $(P=.015)$ as risk factors for postoperative MV dysfunction, Cox multivariate analysis revealed that none of those factors were independently associated with postoperative MV dysfunction (no use of an annuloplasty ring: HR, 1.19; 95\% CI, 0.44$3.19 ; P=.773$; papillary muscle-splitting technique: HR, 2.15; 95\% CI, 0.86-5.39; $P=.102$ ). Rheumatic MV 


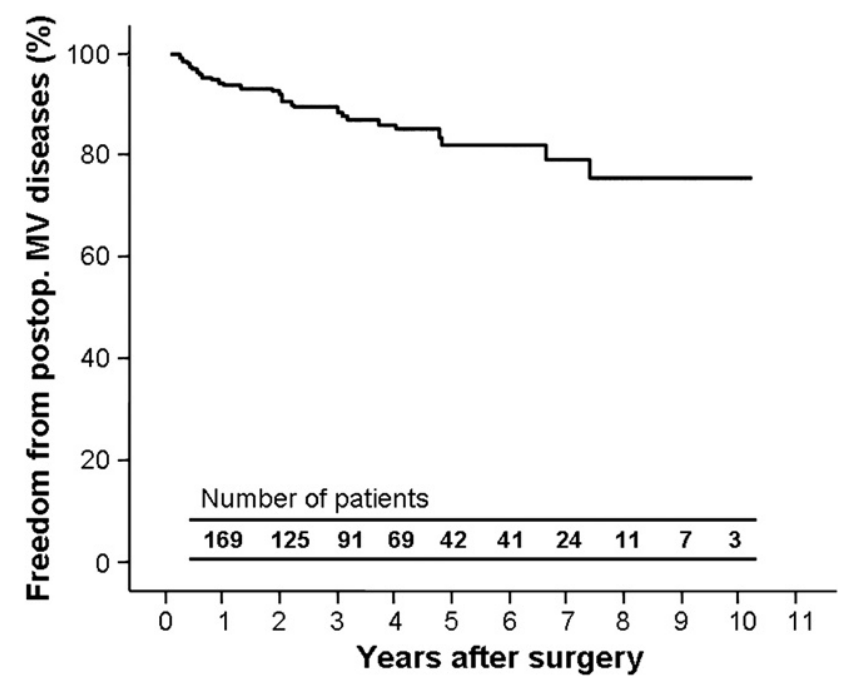

FIGURE 1. Freedom from postoperative mitral valve (postop. $M V$ ) disease. Overall postoperative MV disease-free rates were $84.1 \% \pm 2.7 \%$ at 3 years and $79.0 \% \pm 3.4 \%$ at 5 years.

pathology was not related to postoperative MV dysfunction (HR, 1.39; 95\% CI, 0.62-3.09; $P=.416$ ).

\section{Rhythm Outcomes and Antiarrhythmic Medication}

Thirty-seven $(17.9 \%)$ patients experienced early $\mathrm{AF}$ events (29 in the control group and 8 in the disease group, $P=.468)$. Twenty-eight patients experienced late $(>3$ months) recurrence of AF during follow-up (18 in the control group and 10 in the disease group). Of them, 20 received amiodarone, which resulted in sinus rhythm conversion in all. Of those 20 patients, 11 re-experienced AF recurrence after discontinuation of amiodarone and were restarted on the medication subsequently. Of 8 individuals who were not treated with amiodarone, 2 regained sinus rhythm by means of electrical cardioversion, and 6 were left untreated for AF because they were single episodes detected by means of Holter monitoring without symptoms. None of the patients who experienced late AF recurrence progressed to persistent AF. Another 34 patients had been taking amiodarone from the early postoperative period, and the treatment was eventually discontinued without any episode of late AF recurrence. The overall AF-free rates without antiarrhythmic medication were $89.2 \% \pm 2.3 \%$ at 3 years, $82.0 \% \pm$ $3.5 \%$ at 5 years, and $75.5 \% \pm 5.4 \%$ at 8 years. Late AF recurrence was more frequent in the disease group than in the control group ( $P=.014$, Figure 2$)$.

Univariate risk factor analysis for other variables revealed that a larger preoperative LA size $(>60 \mathrm{~mm}, P=.045)$ and the presence of an early postoperative $\mathrm{AF}$ event $(P=.008)$ were factors associated with late AF recurrence. Cox multivariate analysis revealed that a larger preoperative LA size, the use of microwave ablation rather than cryoablation, and the presence of an early postoperative AF event or postoper-

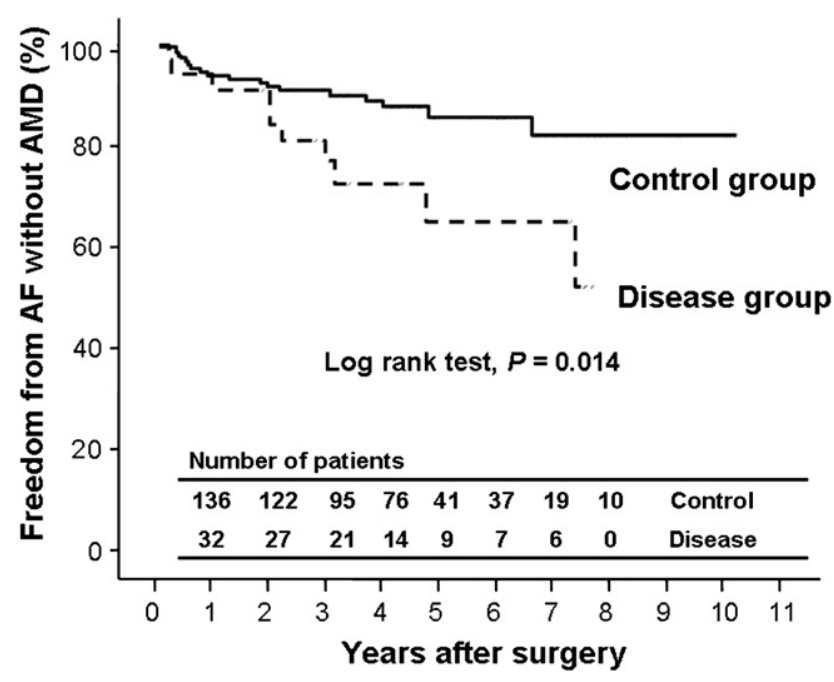

FIGURE 2. Freedom from atrial fibrillation $(A F)$ without amiodarone (AMD). In the control group AF-free rates were $91.1 \% \pm 2.3 \%$ at 3 years and $85.9 \% \pm 3.4 \%$ at 5 years. In the disease group they were $81.1 \% \pm$ $6.9 \%$ at 3 years and $65.2 \% \pm 10.3 \%$ at 5 years.

ative MV disease were independent factors associated with AF recurrence (Table 3).

\section{Postoperative LA Size and Transmitral A-Wave Assessments}

LA size decreased immediately after the operation, from $60.1 \pm 9.7 \mathrm{~mm}$ to $46.6 \pm 6.7 \mathrm{~mm}(P<.001)$, without an intergroup difference $(P=.204)$. LA size was larger in the disease group than in the control group over the 6-month to 3-year period (Figure 3).

The transmitral A-wave prevalence of patients in normal sinus rhythm was $74.5 \%$ to $95.4 \%$. In between-group comparisons differences were found over a postoperative 2- to 3 -year period (Figure 4, $A$ ). There were no significant differences in transmitral A-wave velocity between groups at each postoperative time point up to 4 years (Figure $4, B$ ).

\section{DISCUSSION}

The present study investigated the association between postoperative mitral valvulopathy after mitral repair and maze procedure outcomes. The study found that postoperative mitral valvulopathy was associated with a greater risk of AF recurrence and patients who showed early AF events had more incidence of late AF recurrence than those who did not.

The Cox maze procedure is the most effective surgical procedure for treating $\mathrm{AF}$ and its adverse consequences of irregular rhythm, altered hemodynamics, and increased thromboembolic risk. ${ }^{2,10-12}$ Although the procedure is very effective, it does not resolve AF in all patients. ${ }^{3,5,6,10,11} \mathrm{~A}$ number of studies have reported that of patients who regained sinus rhythm after the maze procedure, some experienced late recurrence of AF, which limits the benefit of the 
TABLE 3. Univariate and multivariate analyses of AF recurrence

\begin{tabular}{|c|c|c|c|c|}
\hline & \multirow{2}{*}{$\frac{\text { Univariate analysis }}{P \text { value }}$} & \multicolumn{3}{|c|}{ Multivariate analysis } \\
\hline & & HR & $95 \%$ CI & $P$ value \\
\hline \multicolumn{5}{|l|}{ Preoperative factors } \\
\hline Age $>60 y$ & .706 & & & \\
\hline $\begin{array}{l}\text { Presence of } \\
\quad \text { coronary disease }\end{array}$ & .814 & & & \\
\hline $\begin{array}{l}\text { Ejection fraction } \\
\quad<50 \%\end{array}$ & .455 & & & \\
\hline $\begin{array}{l}\text { Left atrial size } \\
\quad>60 \mathrm{~mm}\end{array}$ & $.028 *$ & 2.61 & $1.04-6.52$ & $.041 *$ \\
\hline $\begin{array}{l}\text { Cardiothoracic ratio } \\
\quad>60 \%\end{array}$ & .715 & & & \\
\hline $\begin{array}{l}\text { Fine AF-wave } \\
\text { pattern }\end{array}$ & .134 & 2.00 & $0.92-4.34$ & .079 \\
\hline $\begin{array}{l}\text { Persistent vs } \\
\text { paroxysmal AF }\end{array}$ & .271 & & & \\
\hline $\mathrm{AF}$ duration $>5 \mathrm{y}$ & .435 & & & \\
\hline $\begin{array}{l}\text { Rheumatic vs } \\
\text { degenerative }\end{array}$ & .401 & & & \\
\hline $\begin{array}{l}\text { Preoperative MR vs } \\
\quad \text { MS }\end{array}$ & .513 & & & \\
\hline \multicolumn{5}{|l|}{ Operative factors } \\
\hline $\begin{array}{l}\text { Mitral ring } \\
\text { annuloplasty }\end{array}$ & .175 & & & \\
\hline $\begin{array}{c}\text { Microwave ablation } \\
\text { vs cryoablation }\end{array}$ & .080 & 2.33 & $1.03-5.23$ & $.041 *$ \\
\hline $\begin{array}{l}\text { Minimally invasive } \\
\text { approach }\end{array}$ & .058 & & & \\
\hline \multicolumn{5}{|l|}{ Postoperative factors } \\
\hline $\begin{array}{c}\text { Postoperative MV } \\
\text { dysfunction }\end{array}$ & $.014 *$ & 3.67 & $1.48-9.08$ & $.005^{*}$ \\
\hline $\begin{array}{l}\text { Presence of early } \\
\text { AF event }\end{array}$ & $.003^{*}$ & 3.75 & $1.65-8.52$ & $.002 *$ \\
\hline
\end{tabular}

$H R$, Hazard ratio; $C I$, confidence interval; $A F$, atrial fibrillation; $M R$, mitral regurgitation; $M S$, mitral stenosis; $M V$, mitral valve. $* P<.05$.

procedure. The risk factors for late recurrence of $\mathrm{AF}$ after the maze procedure include patient age, longer preoperative $\mathrm{AF}$ duration, fine AF-wave pattern, and increased LA size. ${ }^{3,5,6}$

Long-term pressure and volume overload on the LA wall caused by MV disease induces LA tissue stretching and fibrosis and resultant LA wall thinning and enlargement. ${ }^{3}$ These changes in LA tissue increase susceptibility to AF development. As a result, $\mathrm{AF}$ is observed in $40 \%$ to $60 \%$ of patients who require MV surgery. ${ }^{1}$ Considering the preoperative pathogenesis, it can be speculated that postoperative remnant or recurrent MV disease is likely to increase the risk of $\mathrm{AF}$ recurrence. Although previous studies that analyzed $\mathrm{AF}$ recurrence after the maze procedure mainly investigated which preoperative factor might affect $\mathrm{AF}$ recurrence, ${ }^{3,5,6}$ the present study is the first to examine the association between postoperative mitral valvulopathy and rhythm outcomes. Univariate and multivariate analyses confirmed the association between postoperative mitral dysfunction and late AF recurrence, and the sequentiality of

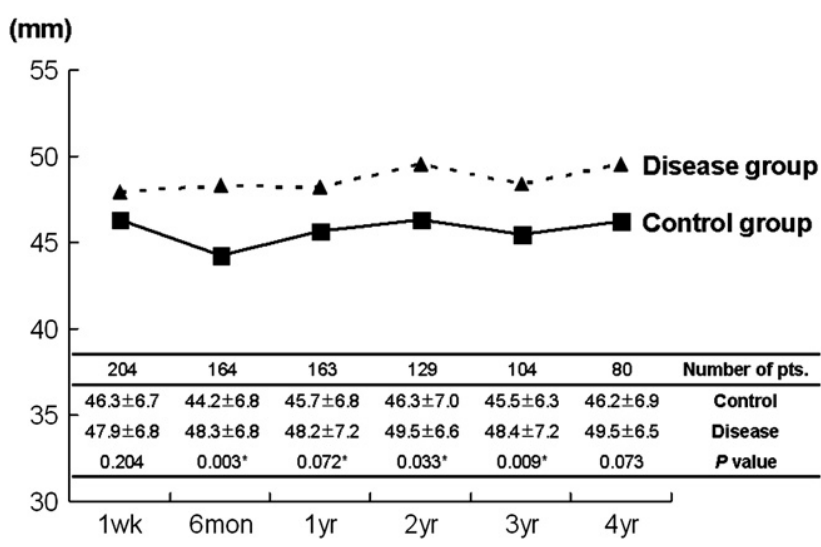

FIGURE 3. Postoperative changes in left atrial dimension (in millimeters). Left atrial size was significantly larger in the disease group than in the control group over a 6-month to 3-year period.

events was in the order of AF recurrence following the MV dysfunction. These results strongly suggest that postoperative MV dysfunction negatively affects the rhythm outcomes after the combination of MV repair and the maze procedure.

In the present study LA size was significantly larger in the disease group than in the control group in most postoperative periods. However, postoperative LA size was about 47 to 50 $\mathrm{mm}$ in the disease group, and intergroup discrepancy in LA size was about $4 \mathrm{~mm}$, which is not similar to the degree of LA enlargement seen in patients with MV disease who have AF in general. This relatively small between-group difference in LA size might be explained by LA wall resection performed during the maze procedure. With the same amount of volume and pressure load, the effect of LA enlargement is expected to be reduced if the LA wall mass is reduced.

The present study revealed that patients who had early $\mathrm{AF}$ events had more than 3 times the incidence of late AF recurrence than those who did not (HR, 3.75). It seems to be a significant finding that the rhythm status in the early postoperative period has a strong predictive value in the long-term rhythm outcome after the maze procedure. This finding suggests that patients who have early AF events should not be regarded as they are in a transient state in the postablation blank period but should be carefully monitored for late $\mathrm{AF}$ recurrence in the long-term.

Since the introduction of standardized techniques for MV reconstruction, $\mathrm{MV}$ repair has become the surgical treatment of choice for MR. ${ }^{13}$ Although repair durability is acceptable for most patients, some require late reoperation for recurrent MV dysfunction. ${ }^{14-18}$ A study evaluated MR recurrences using echocardiographic follow-up after mitral repair and found that freedom from recurrence of nontrivial MR was $58.6 \%$ at 5 years and only $27.2 \%$ at 7 years. ${ }^{14}$ In that study the linearized recurrence rate of MR of greater than grade 1 was $6.9 \%$ per year, and that of MR of greater than grade 2 

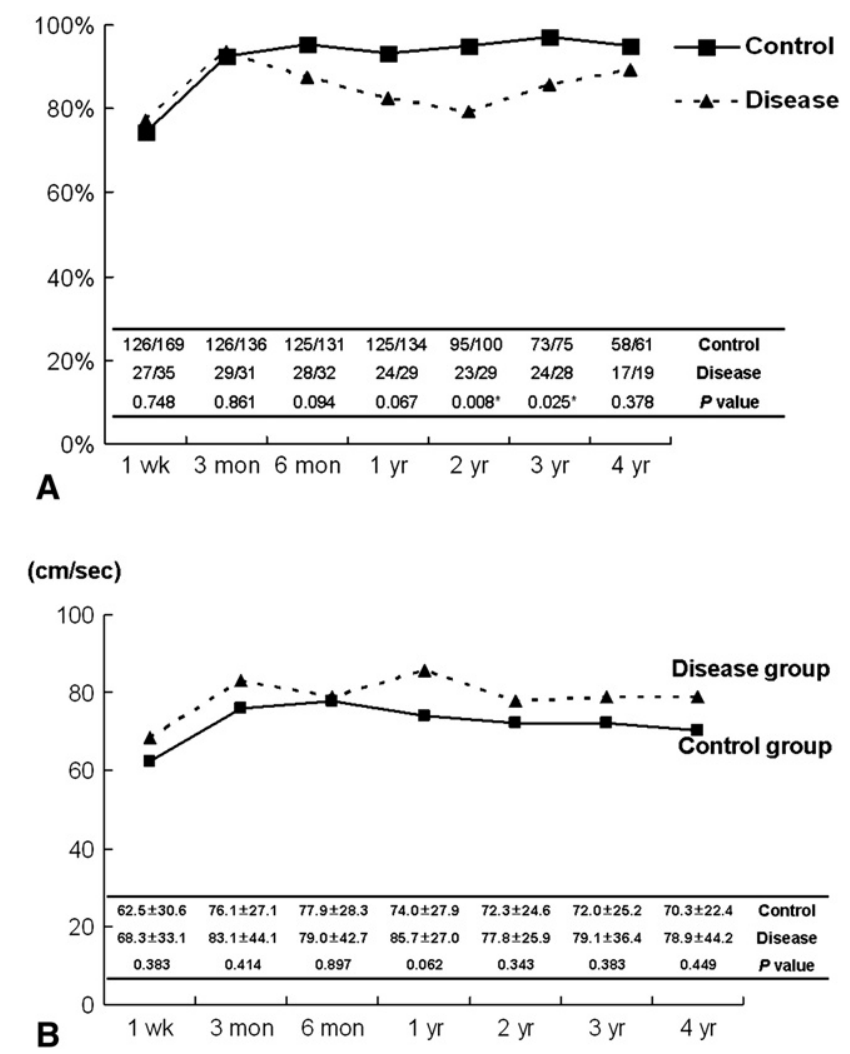

FIGURE 4. Transmitral A-wave prevalence (A) and velocity (B). Beyond the immediate postoperative period, A-wave prevalence was maintained at greater than $80 \%$ up to 4 years. In intergroup comparisons the differences were found over a 2- to 3-year period, with a lower A-wave prevalence in the disease group. There were no significant differences in transmitral A-wave velocity between groups throughout the postoperative period.

was $2.5 \%$ per year. These findings strongly suggest progression of the degenerative process over time. In the present study the presence of postoperative MV disease was defined by using echocardiographic data and was presented as a time-related event to precisely delineate the relationship between postoperative MV dysfunction and $\mathrm{AF}$ recurrence. Of the 39 patients who had postoperative MV disease, the disease was detected in only 6 before hospital discharge, whereas it was detected in the remaining 33 patients during follow-up. If we had defined the risk group according to the immediate postoperative echocardiographic assessment only, those patients with late recurrence of MV disease would have been included in the control group, which in turn would have created a misinterpretation regarding the relationship between postoperative MV dysfunction and AF recurrence. The finding that MV dysfunction was mostly detected after discharge reflects that the recurrence of MV disease after MV repair is an ongoing process, which is consistent with a previously reported study. ${ }^{14}$ The findings highlight that even when initial echocardiographic assessment indicates successful MV repair, careful long-term follow-up echocardiographic analysis is required to assess any MV function deterioration. These efforts seem to be necessary not only for the selection of reoperation candidates but also for predicting AF recurrence, which heightens the risk of lethal thromboembolic complications.

Another interesting finding in this study is that the use of microwave ablation resulted in greater AF recurrence compared with cryoablation. Although a number of studies had reported excellent results with the use of microwave ablation in AF ablation surgery, those studies have recorded followup rhythm data for only less than 1 year. ${ }^{19-21}$ This is quite contrary to cryoablation, for which long-term results have shown similar results as seen with the conventional cutand-sew Cox maze procedure in terms of restoration and maintenance of sinus rhythm. ${ }^{4,22,23}$ To our knowledge, only 1 study has investigated the long-term ( $>1$ year) outcomes of LA endocardial microwave ablation. ${ }^{24}$ In that study, with a mean follow-up duration of $5.37 \pm 0.91$ years, only $39.3 \%$ of patients were in sinus rhythm after 5 years. The authors concluded that microwave ablation is not a reliable method for achieving long-term conversion to sinus rhythm because of a lack of lesion transmurality. In support of their hypothesis, a postmortem histologic study in which 3 patients underwent microwave ablation for the treatment of $\mathrm{AF}$ showed that in autopsies performed within 22 days of surgical intervention, the atrial lesions were not transmural and the extent of myocardial damage was highly variable. ${ }^{25}$

The result of the present study also raises a question on the efficacy of microwave ablation. Because there has been no study comparing the long-term effect of microwave ablation and cryoablation, further studies are necessary to verify the result from the present study.

\section{Limitations}

This study is subject to the limitations inherent to retrospective observational data studies. Efforts made to overcome such limitations included prospective data collection and storage of data in a designed and regimented database. The purpose of this study was to delineate the influence of postoperative MV dysfunction on $\mathrm{AF}$ recurrence in the long-term after surgical intervention. Therefore patients who initially did not have restored sinus rhythm were excluded from the analyses. This patient selection might have led to the difference with results from other studies, which reported the clinical significances of patients' preoperative conditions on the rhythm outcomes after the maze procedure.

LA size dilatation caused by MV disease is the most important phenomenon in the pathogenesis of AF development. However, AF itself has the effect of LA chamber enlargement when assessed by means of echocardiography or other imaging studies. In our study we could not determine whether an increase in LA size in the disease group was the result of postoperative MV dysfunction or 
a phenomenon caused by AF recurrence. To address this issue, patients should be grouped into 4 groups according to the presence or absence of postoperative MV dysfunction and AF recurrence, respectively, and LA size should be compared between the groups. However, there were only 11 patients who showed recurrent $\mathrm{AF}$ in the disease group and only 18 patients in the control group. This sample size was too small to generate statistical power when serial changes in LA size were compared between the groups. Such analysis requires a larger patient population.

The measurement of LA dimension was used in the present study; however, LA volume index might be a better indicator of LA size, which takes into account the patient's body surface area.

\section{CONCLUSIONS}

Postoperative MV dysfunction and early AF events were found to be independent factors associated with late $\mathrm{AF}$ recurrence after MV repair combined with the maze procedure. Patients with postoperative MV dysfunction had a greater LA size throughout the postoperative period than those without MV dysfunction. Any patient with MV dysfunction postoperatively should be closely monitored for $\mathrm{AF}$ recurrence and adequately managed.

\section{References}

1. Feinberg MS, Waggoner AD, Kater KM, Cox JL, Lindsay BD, Perez JE. Restoration of atrial function after the maze procedure for patients with atrial fibrillation. Assessment by Doppler echocardiography. Circulation. 1994;90(suppl): II285-92.

2. Bando K, Kobayashi J, Hirata M, Satoh T, Niwaya K, Tagusari O, et al. Early and late stroke after mitral valve replacement with a mechanical prosthesis: risk factor analysis of a 24-year experience. J Thorac Cardiovasc Surg. 2003;126:358-64.

3. Kamata J, Kawazoe K, Izumoto H, Kitahara H, Shiina Y, Sato Y, et al. Predictors of sinus rhythm restoration after Cox maze procedure concomitant with other cardiac operations. Ann Thorac Surg. 1997;64:394-8.

4. Itoh A, Kobayashi J, Bando K, Niwaya K, Tagusari O, Nakajima H, et al. The impact of mitral valve surgery combined with maze procedure. Eur J Cardiothorac Surg. 2006;29:1030-5.

5. Gillinov AM, Sirak J, Blackstone EH, McCarthy PM, Rajeswaran J, Pettersson G, et al. The Cox maze procedure in mitral valve disease: predictors of recurrent atrial fibrillation. J Thorac Cardiovasc Surg. 2005;130:1653-60.

6. Kim KC, Cho KR, Kim YJ, Sohn DW, Kim KB. Long-term results of the Cox-Maze III procedure for persistent atrial fibrillation associated with rheumatic mitral valve disease: 10-year experience. Eur J Cardiothorac Surg. 2007;31: 261-6.

7. Lee JW, Choo SJ, Kim KI, Song JK, Kang DH, Song JM, et al. Atrial fibrillation surgery simplified with cryoablation to improve left atrial function. Ann Thorac Surg. 2001;72:1479-83.
8. Calkins H, Brugada J, Packer DL, Cappato R, Chen SA, Crijns HJ, et al. HRS/ EHRA/ECAS expert Consensus Statement on catheter and surgical ablation of atrial fibrillation: recommendations for personnel, policy, procedures and follow-up. A report of the Heart Rhythm Society (HRS) Task Force on catheter and surgical ablation of atrial fibrillation. Heart Rhythm. 2007;4:816-61.

9. Altman DG, De Stavola BL. Practical problems in fitting a proportional hazards model to data with updated measurements of the covariates. Stat Med. 1994;13: $301-41$.

10. Izumoto H, Kawazoe K, Kitahara H, Kamata J. Operative results after the Cox/ maze procedure combined with a mitral valve operation. Ann Thorac Surg. 1998;66:800-4

11. Bando K, Kasegawa H, Okada Y, Kobayashi J, Kada A, Shimokawa T, et al. Impact of preoperative and postoperative atrial fibrillation on outcome after mitral valvuloplasty for nonischemic mitral regurgitation. J Thorac Cardiovasc Surg. 2005; 129:1032-40.

12. Cox JL, Ad N, Palazzo T, Fitzpatrick S, Suyderhoud JP, DeGroot KW, et al. Current status of the Maze procedure for the treatment of atrial fibrillation. Semin Thorac Cardiovasc Surg. 2000;12:15-9.

13. Pomar JL, Ubago JL, Colman T, Figueroa A, Revuelta JM, Duran CM. [Analysis of the results of 212 flexible annuloplasties in mitral position]. Rev Esp Cardiol. 1980;33:227-33.

14. Flameng W, Herijgers P, Bogaerts K. Recurrence of mitral valve regurgitation after mitral valve repair in degenerative valve disease. Circulation. 2003;107: 1609-13.

15. Cohn LH, Couper GS, Aranki SF, Rizzo RJ, Kinchla NM, Collins JJ Jr. Long-term results of mitral valve reconstruction for regurgitation of the myxomatous mitral valve. J Thorac Cardiovasc Surg. 1994;107:143-50.

16. Gillinov AM, Cosgrove DM, Blackstone EH, Diaz R, Arnold JH, Lytle BW, et al. Durability of mitral valve repair for degenerative disease. $J$ Thorac Cardiovasc Surg. 1998;116:734-43.

17. Chung CH, Kim JB, Choo SJ, Kim KS, Song H, Song MG, et al. Long-term outcomes after mitral ring annuloplasty for degenerative mitral regurgitation: Duran ring versus Carpentier-Edwards ring. J Heart Valve Dis. 2007;16:536-44.

18. Gillinov AM, Cosgrove DM 3rd. Current status of mitral valve repair. Am Heart Hosp J. 2003;1:47-54.

19. Knaut M, Tugtekin SM, Spitzer SG, Jung F, Matschke K. Intraoperative endocardial microwave ablation for treatment of permanent atrial fibrillation during coronary artery bypass surgery: 1-year follow-up. Europace. 2006;8:16-20.

20. Topkara VK, Williams MR, Barili F, Bastos R, Liu JF, Liberman EA, et al. Radiofrequency and microwave energy sources in surgical ablation of atrial fibrillation: a comparative analysis. Heart Surg Forum. 2006;9:E614-7.

21. Wisser W, Khazen C, Deviatko E, Stix G, Binder T, Seitelberger R, et al. Microwave and radiofrequency ablation yield similar success rates for treatment of chronic atrial fibrillation. Eur J Cardiothorac Surg. 2004;25:1011-7.

22. Bando K, Kobayashi J, Kosakai Y, Hirata M, Sasako Y, Nakatani S, et al. Impact of Cox maze procedure on outcome in patients with atrial fibrillation and mitral valve disease. J Thorac Cardiovasc Surg. 2002;124:575-83.

23. Nakajima H, Kobayashi J, Bando K, Niwaya K, Tagusari O, Sasako Y, et al. The effect of cryo-maze procedure on early and intermediate term outcome in mitral valve disease: case matched study. Circulation. 2002;106(suppl 1):I46-50.

24. Vicol C, Kellerer D, Petrakopoulou P, Kaczmarek I, Lamm P, Reichart B. Longterm results after ablation for long-standing atrial fibrillation concomitant to surgery for organic heart disease: is microwave energy reliable? J Thorac Cardiovasc Surg. 2008;136:1156-9.

25. Accord RE, van Suylen RJ, van Brakel TJ, Maessen JG. Post-mortem histologic evaluation of microwave lesions after epicardial pulmonary vein isolation for atrial fibrillation. Ann Thorac Surg. 2005;80:881-7. 